Sri Lanka J. Aquat. Sci. 15 (2010): 25-38

\title{
Vegetative propagation of some selected mangrove species from Negombo estuary, Sri Lanka
}

\author{
K.H.W.L. de SILVA* and M.D.AMARASINGHE \\ Department of Botany, University of Kelaniya, Kelaniya, Sri Lanka. \\ *Corresponding author (E-mail: wasana_cbc@yahoo.com)
}

\begin{abstract}
Mangrove forests are degraded and threatened worldwide, due to anthropogenic events. Mass production of planting material and successful germination of seeds are essential processes in rehabilitating these degraded mangrove forests. The present work was carried out to determine the efficacy of using propagule cuttings in mass production of plant materials and to determine the potential of using non mangrove soils to establish propagule cuttings for ornamental purposes. In addition air layering and stem cutting techniques were also tested for the mangrove propagation.

Propagation of Rhizophora apiculata, by propagule cuttings, treated with root promoting hormones is feasible and it was possible to produce three saplings from one propagule. Indole Butyric Acid (IBA) (1000 ppm) was the best hormone concentration for inducing roots and IBA $(1500 \mathrm{ppm})$ was the best for inducing shoots from propagule cuttings of $R$. apiculata. Air layering and stem cutting were performed with Avicennia marina and $R$. apiculata but none of the species was able to generate roots and therefore these vegetative propagation methods cannot be used for mass propagation of these mangrove species. Optimum growth medium and period of nursery care for mangrove saplings of $R$. apiculata, Ceriops tagal and Bruguiera sexangula were studied and the results revealed that best growth performance was in mangrove soils, i.e. $4.15 \mathrm{~cm} / 4$ weeks for $R$. apiculata, $3.75 \mathrm{~cm} /$ 4weeks for $B$. sexangula and $0.56 \mathrm{~cm} / 4$ weeks for $C$. tagal, while mangrove soils mixed with sand produced the second best growth for C. tagal and B. sexangula. Seedlings grown on terrestrial soils showed the lowest growth rate for all three mangrove species. However, no significant difference $(\mathrm{P}<0.05)$ exists in growth rates of mangrove seedlings when grown in different growth media, indicating they can be grown with terrestrial soil for ornamental purposes.

Potting media consisted only of mangrove soils as well as mangrove soils (1): sand (1), terrestrial soil alone and mangrove soil (1): terrestrial soil (1) can be used as nursery growth media for R. apiculata and C. tagal.
\end{abstract}




\section{Introduction}

Over the past years, mangrove habitats have been severely degraded take place heavily throughout the world and it was estimated that about one-third of the world's mangrove forests are lost due to a number of causes, of which, unrestricted clear felling, aquaculture, and overexploitation for fisheries will continue to be the greatest threats of mangrove forests in the next 25 years (Alongi 2002). This has led to considerable attention on mangrove regeneration both in national and global levels. This trend gathered an unprecedented momentum in the aftermath of Indian Ocean tsunami in 2004.

Mangroves are mainly regenerated through propagules and seeds. Pre and post dispersal predation of mangrove propagules are common (Peter and Raelee 2002; Minchinton 2001). Predation of mangrove juveniles can involve decapods, snails, insects, monkeys and fish have found to be the major predators (DahdouhGuebas et al. 1998). As such, there are natural threats to regeneration of some mangrove species and therefore vegetative propagation is one of the best methods of producing a large number of new plants from vegetative parts of the mother plant (Selvam et al. 2005). Moreover, when mangrove planting does not coincide with the reproductive season of the mangrove plants, vegetative propagation would be an ideal method to supply planting material throughout the year. Stem cutting and air layering are the other major methods of vegetative propagation. In addition, it is believed that mangroves can propagate vegetatively through propagule cuttings too where propagules are cut into pieces and each one would grow into a sapling separately (Selvam et al. 2005).

Since seed/ seedling predators hamper natural establishment of seedlings, raring mangrove seedlings upto sapling stage in nurseries is an ideal strategy to minimize this predator damage and to facilitate vigorous growth. Therefore nursery -reared seedlings provide a promising source of planting material for mangrove reforestation programmes. Nurseries can be developed in polythene bags and maintained in areas close to supra-tidal zone in estuaries and lagoons under shady conditions for 6 months to one year (Amarsinghe and Vidanage 2007). In addition, mangrove nurseries provide extra job opportunities and livelihoods for coastal dwellers. Potted mangrove plants could also be used for ornamental purposes. Nevertheless, the issue of selecting a suitable culture medium other than mangrove soils for the purpose has to be addressed.

The present study therefore, was carried out to determine the best vegetative propagation method/s for some selected mangrove species that could be used for mangrove cultivation and also for horticultural purposes.

\section{Materials and Methods}

Avicennia marina, Aegiceras corniculatum, Bruguiera sexangula, Ceriops tagal, Rhizophora apiculata and $R$. mucronata are the mangrove species investigated for the feasibility of vegetative propagation through air layering, stem cutting and propagule cutting supported with growth promoting hormones. $R$. apiculata, $C$. tagal and B. sexangula were used to identify the appropriate medium 
for nursery raring of mangrove propagules. Plant materials were brought from the Negombo lagoon and the examination was carried out at the laboratory and botanical garden at the University of Kelaniya.

\section{Mangrove propagation through propagule cuttings}

Propagules of $R$. apiculata and $C$. tagal were cut into $4-5 \mathrm{~cm}$ pieces and propagules of $A$. coniculatum were cut into $2-2.5 \mathrm{~cm}$ pieces. Phenolic compounds present in cuttings were removed using $10 \%$ and $5 \%$ phenol removing solutions. A volume of $100 \mathrm{ml}$ phenol-removing stock solution (20\%) was prepared by dissolving $20 \mathrm{~g}$ of sodium carbonate and $20 \mathrm{~g}$ of sodium tungstate and it was used to prepare $10 \%$ and $5 \%$ phenol removing working solutions (PRWS). A volume of $50 \mathrm{ml}$ of from the stock solution $(20 \%)$ was mixed with $50 \mathrm{ml}$ of distilled water to prepare $10 \%$ PRWS and $25 \mathrm{ml}$ of stock solution was mixed with $75 \mathrm{ml}$ of distilled water to prepare the 5\% PRWS (Selvam et al. 2005).

The basal portion of the cuttings was immersed in 10\% PRWS for 5-10 mins. After the phenol removing treatments, propagule cuttings were washed 2-3 times by distilled water. Then Indole Butric Acid (IBA) and Naphthalene Acetic Acid (NAA) hormone stock solutions (10000 ppm) were prepared separately by adding $1 \mathrm{~g}$ of each hormone into $100 \mathrm{ml}$ volumetric flasks and then $1 \mathrm{~N} \mathrm{NaOH}$ was added drop-wisely until the solids dissolved completely. Finally distilled water was added to bringing the volume to $100 \mathrm{ml}$. Using this stock solution of $10000 \mathrm{ppm}$ treatment solutions of 100,500,1000,1500, 2000 ppm were prepared. Combination of IBA and NAA (100:500, 500:1000, 1000:500, 1500:1000, and 2000:1500) were prepared and basal portion of the propagule cuttings were dipped in each of the root promoting hormone solutions, IBA, NAA and both IBA and NAA for 10-30 mins. Six replicates from each treatment together with six replicates of control were made without root hormone application.

Treated seedling cuttings were planted in polythene bags containing a mixer of mangrove soil and coir dust made at 1:1 ratio. Then white paint was applied on the exposed portion of the cuttings to reduce fungal attacks if any. Each replicate was tagged. Planted cuttings were placed in a shady place in the university botanical garden. Cuttings were continuously monitored and fresh water was supplied when necessary. Root length of the propagule cuttings were measured after 1 and 2 months.

\section{Mangrove propagation through air layering}

Semi- hard wood or hard wood branches of A. marina and $R$. apiculata trees were used for air layering experiments. The in situ experiments for air layering were performed at Kadalkele mangrove area. Outer bark of the selected branch was removed $2-5 \mathrm{~cm}$ below the node using a fine blade. A bridge of the bark was made to a 2-4 mm thickness in a way to connect upper end of the mother plant and lower end of the daughter plant. Hormones, IBA only, NAA only or both IBA and NAA were applied twice all around the wounded portion using a fine brush. Then rooting medium was prepared by adding 5:2 ratios of coir dust and sand, wet it with lagoon 
brackish water and mixed well. This rooting medium was applied around the wounded portion and wrapped using a transparent polythene sheet. Finally two ends of the polythene sheet were tightly bound by twine threads. Six similar replicates were prepared with together with six replicates of control where no root hormones were added. All the replicates were tagged and were continuously monitored and watered when necessary.

\section{Mangrove propagation through stem cuttings}

A. marina and $R$. apiculata stem cuttings were used for hormone treatments. Semi hard wood or hard wood branches were selected from both species. These branches were cut into $15-20 \mathrm{~cm}$ length pieces. The basal portions of the cuttings were immersed in a 10\% phenol removing solution for 5-10 mins and washed 2-3 times with distilled water. Basal portions of the stem cuttings were dipped separately in a solution containing a root promoting hormones, IBA only, NAA only and with both IBA and NAA for 10-30 mins. Six replicates were used for each hormone concentration. In addition, six control replicates were also prepared without application of root hormones. Then the cuttings were planted in polythene bags containing mangrove soil and white paint was applied on their exposed portions to reduce if there is any fungal attack. Each replicate was tagged. Planted cuttings were placed in a shady place in the university botanical garden. Planted cuttings were continuously monitored and watered when necessary.

\section{Suitable nursery growth media and optimal period of nursery care}

Growth rates of $R$. apiculata, C. tagal and B. sexangula were monitored with different soil types, i.e. mangrove soil, mangrove soils (1): sand (1), terrestrial soil, mangrove soil (1): terrestrial soil (1). Mature propagules of the above species were then planted in polythene bags containing different soil types and they were kept in the university botanical garden. Growth rate of seedlings was measured by obtaining height increment of shoots every week for 30 weeks. Data were analyzed with One way ANOVA in SPSS 16 at $\alpha=0.05$.

\section{Results}

\section{Mangrove propagation through air layering and stem cutting}

Stem cuttings and air-layered A. marina and $R$. apiculata could not produce new roots, even in the presence of growth hormones.

\section{Mangrove propagation through propagule cuttings}

Mean root and shoot lengths produced by various combinations of IBA and NAA are graphically presented in Figures 1 and.2. Results revealed that among the two hormones (IBA and NAA) and combination of these two auxins, IBA (1000 $\mathrm{ppm})$ induced the best root production, i.e. $4.39 \pm 0.04 \mathrm{~cm}$ while IBA $(1500 \mathrm{ppm})$ 
induce the best shoot production, i.e. $16.5 \pm 0.57 \mathrm{~cm}$ of $R$. apiculata propagule cuttings.

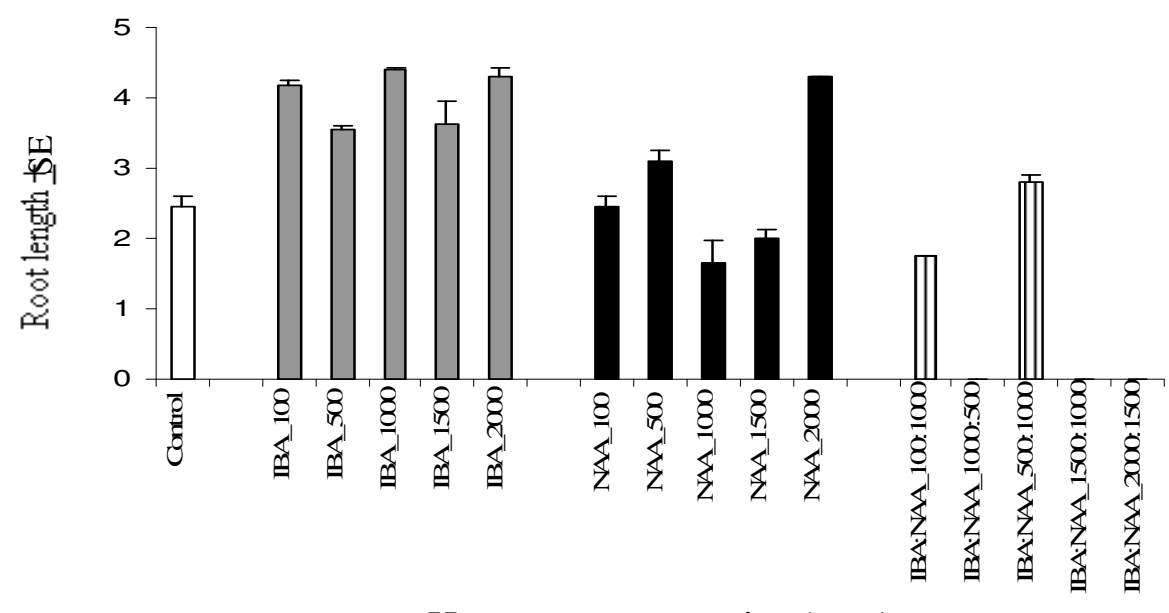

Hormone concentration (ppm)

Figure 1. Root elongation of $R$. apiculata propagule cuttings treated with IBA, NAA and IBA: NAA combination. Mean root lengths $(\mathrm{cm}) \pm \mathrm{SE}$ are presented.

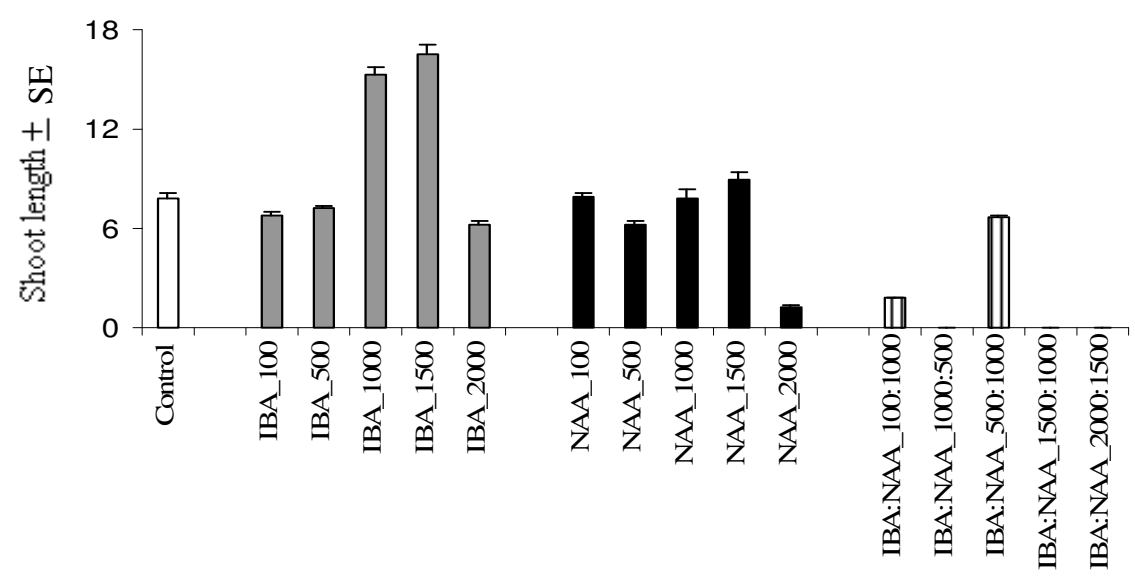

Hormone concentration (ppm)

Figure 2. Shoot elongation of $R$. apiculata propagule cuttings treated with IBA, NAA and IBA: NAA combination. Mean shoot lengths $(\mathrm{cm}) \pm$ SE are presented.

Greater root lengths of propagule cuttings were obtained when IBA alone was used than when IBA and NAA applied together. When cuttings were treated 
with both hormones, the maximum root length was observed with the $500 \mathrm{ppm}$ IBA and $1000 \mathrm{ppm}$ NAA, mixture where the mean root length of $2.8 \mathrm{~cm}$. Cuttings treated with both hormones developed the maximum number of roots per cutting. Cuttings treated with NAA produced the maximum root length, i.e. $4.29 \pm 0.1 \mathrm{~cm}$ when treated with $2000 \mathrm{ppm}$.

$R$. apiculata propagule cuttings treated with hormones, alone or in combination as did not show a significant effect on root and shoot elongation of the seedlings $(\mathrm{P}<0.05$ Scheffe's pair wise test $)$.
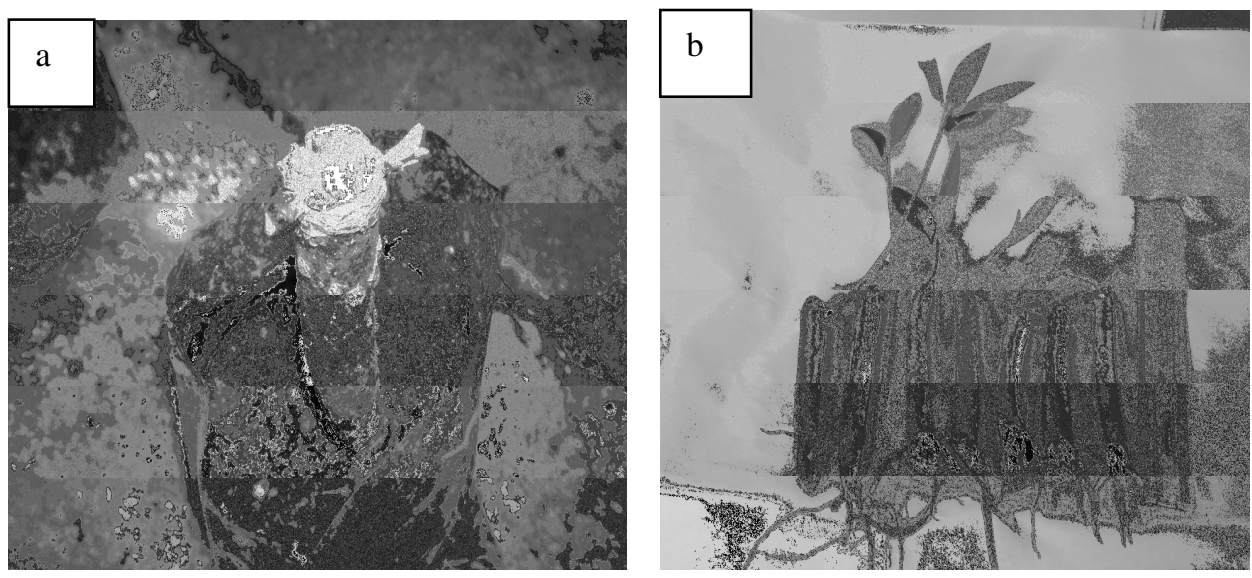

Plate 1. Propagule cuttings $-R$. apiculata

Plate $1 \mathrm{~b}$ shows the $R$. apiculata seedlings obtained from propagule cuttings. It was taken 25 to 30 days to initiate root primodia of all hormone treated cuttings and 4060 days to develop shoot primodia. Plate 1a shows the shoot primodial initiation of $R$. apiculata propagule cuttings.

\section{Percentage survival of cuttings}

Percentage survival of propagule cuttings are graphically presented in Fig. 3. The best percentage survival i.e. $100 \%$ was obtained from IBA $1000 \mathrm{ppm}$. while survival is low in NAA treated and combination of IBA and NAA treated. C. tagal propagule cuttings took a longer time than $R$. apiculata propagule cuttings to develop root primodia. Rooting response of the bottom cuttings were observed 2530 days after planting. It was taken $40-45$ days to initiate root primodia in mid cuttings. However almost all the top cuttings died within the study period. Because of high mortality of cuttings, it was not possible to produce viable planting material out of C. tagal propagules. Initiation of shoot primodia was not observed within the study period. Propagule cuttings of $A$. corniculatum did not produce any root primodia. 


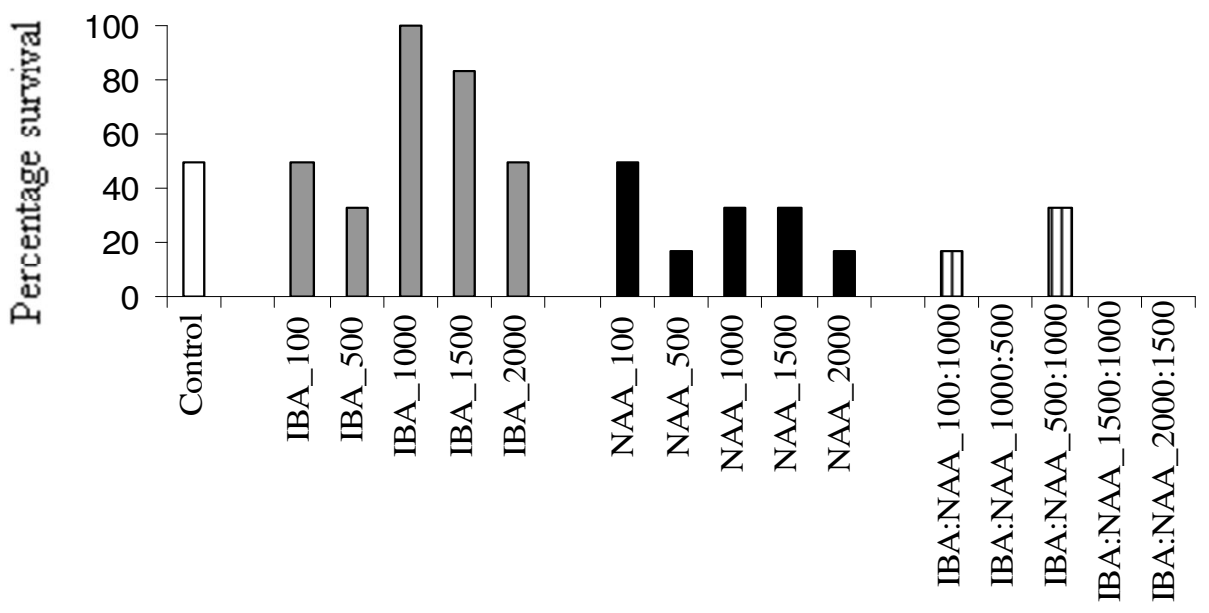

Hormone treatment (ppm)

Figure 3. Percentage survival of $R$. apiculata propagule cuttings treated with IBA, NAA and IBA: NAA combination for the 2 month old seedlings/propagules.

\section{Suitable nursery growth media and period of nursery care}

Suitability of potting media was determined by the plant growth performance in terms of shoot height of the planted seedlings.

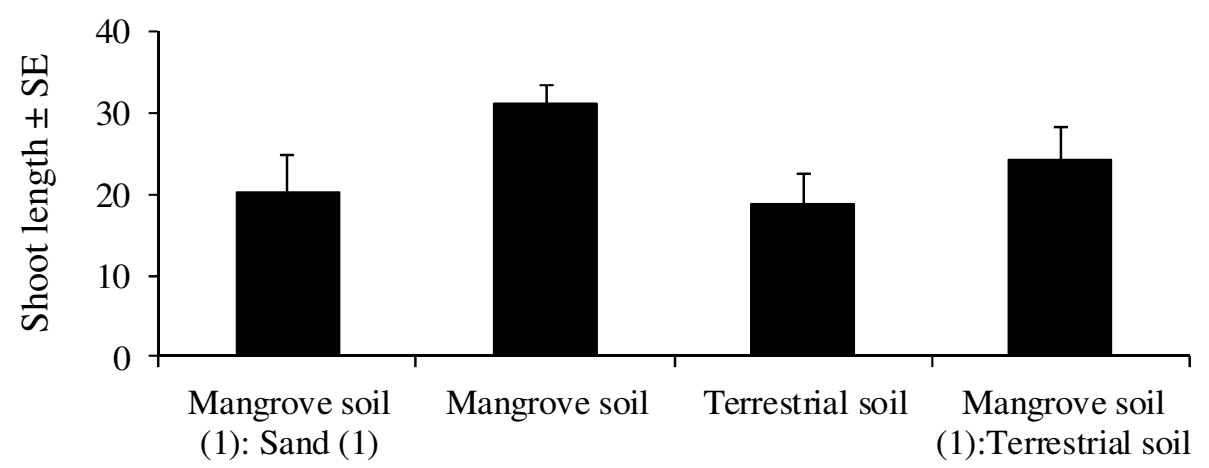

(1)

Substerate type

Figure 4. Shoot height of $R$. apiculata seedlings grown in different substrates. Mean shoot height $(\mathrm{cm}) \pm \mathrm{SE}$ are presented.

R. apiculata seedlings grown on mangrove soil showed the highest mean shoot height i.e. $31.1 \pm 2.25 \mathrm{~cm}$ than that of other substrates. Terrestrial soil (1): Mangrove soil (1) combination showed second best shoot height i.e. $24.2 \pm 4.1 \mathrm{~cm}$ while the lowest was obtained from terrestrial soil. Though different substrates 
showed different shoot heights for $R$. apiculata, the mean shoot heights were not significantly different $(\mathrm{P}<0.05$, One way ANOVA).

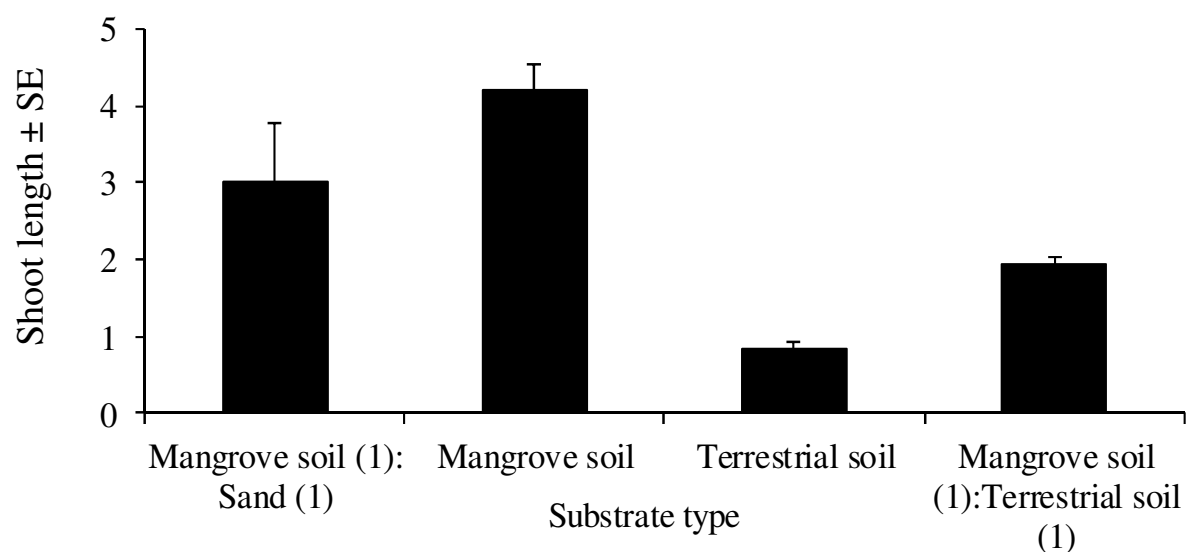

Figure 5. Shoot height of $C$. tagal seedlings grown in different substrates. Mean shoot height $(\mathrm{cm}) \pm \mathrm{SE}$ are presented.

C. tagal seedlings grown on mangrove soil produced the highest mean shoot height than that of other substrates i.e. $4.2 \pm 0.34 \mathrm{~cm}$. Mangrove soil (1): Sand (1) combination produced the second best shoot height i.e. $3 \pm 0.78 \mathrm{~cm}$ while the lowest was obtained from Terrestrial soil.

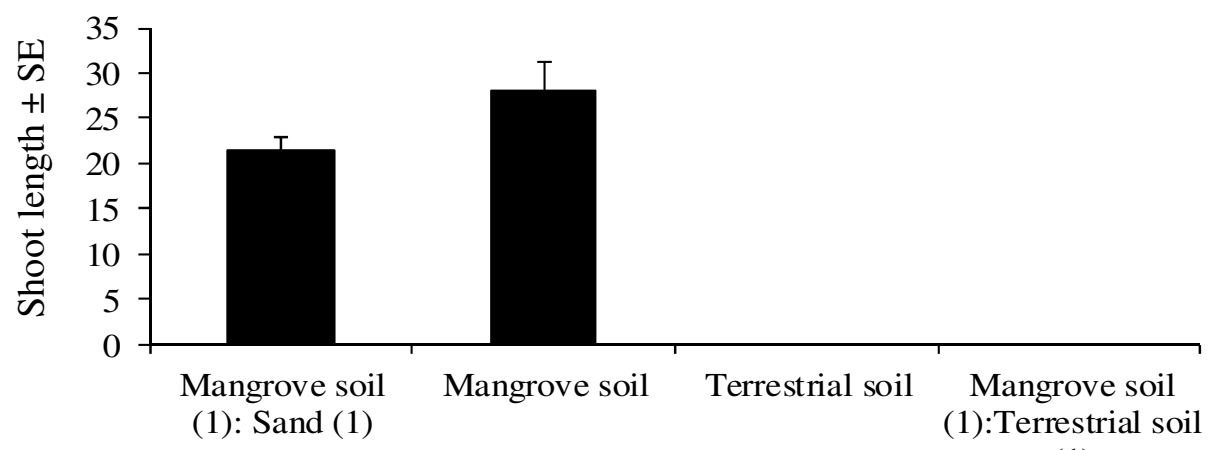

Substrate type

(1)

Figure 6. Shoot height of $B$. sexangula seedlings grown in different substrata. Mean shoot height $(\mathrm{cm}) \pm \mathrm{SE}$ are presented.

B. sexangula seedlings grown on mangrove soil produced the highest mean shoot height than that of other substrates i.e. $28.15 \pm 3.18 \mathrm{~cm}$. None of the propagules grown on terrestrial soil and terrestrial soil (1): mangrove soil (1) was germinated during growth period. Though $B$. sexangula grew well on mangrove soil, mean 
shoot height of Mangrove soil (1): Sand (1) combination was not significantly different with that of only Mangrove soil medium at level of 0.05 .

\section{Growth rates of mangrove seedling in growth media under nursery conditions}

Growth pattern of seedlings of $R$. apiculata, $C$. tagal and B. sexangula during the period of the experiment are presented in Figure 7.

(a)

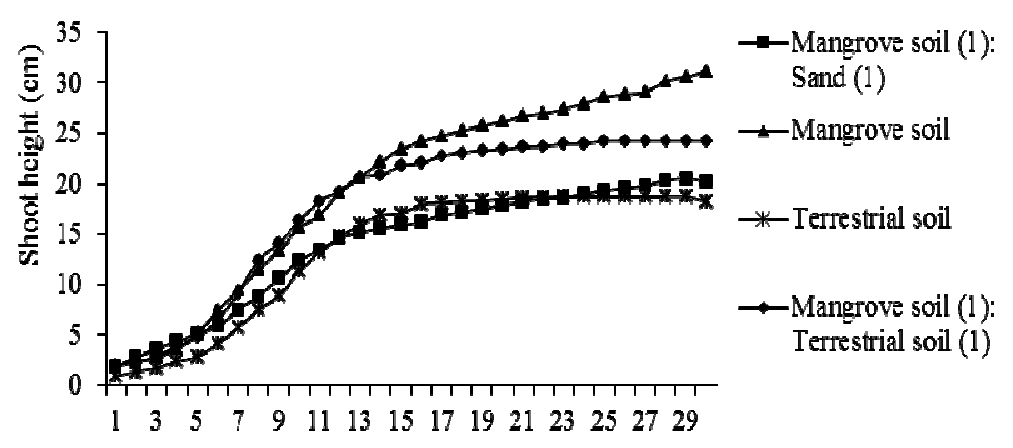

(b)

Growth period(Week)

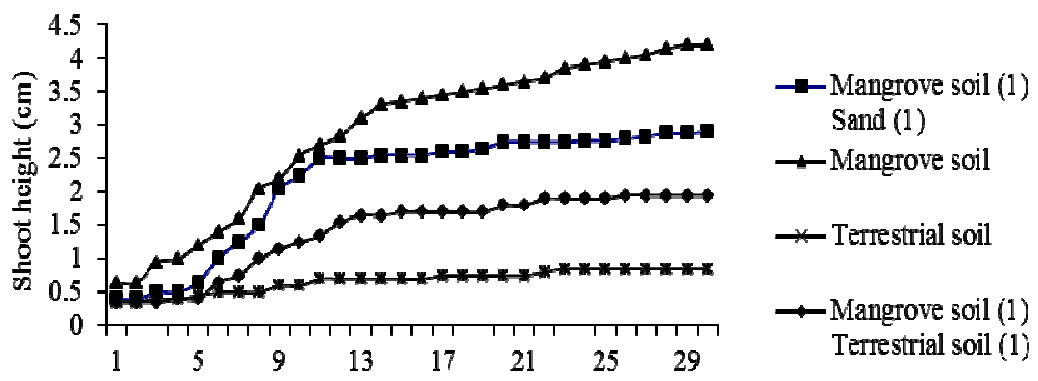

(c)

Growth period (Week)

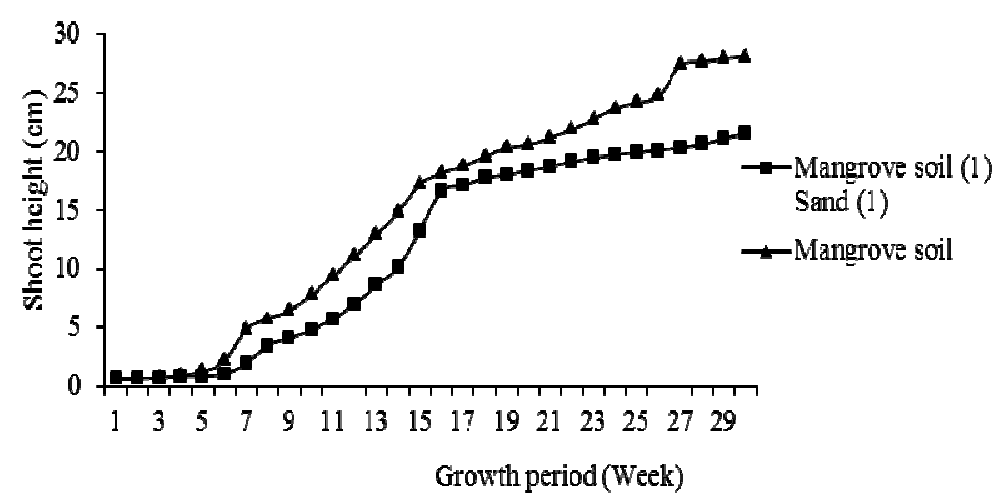

Figure 7. Growth pattern of the seedlings of R. apiculata (a), C. tagal (b) and B. sexangula (c) during the 30 week study period 
All seedlings showed growth pattern i.e. sigmoid growth curve, to some extent which consists with four phases, i.e. lag phase, log phase, diminishing phase and steady state (Soni 2010). Each seedling grew rapidly in the early period and after some time the shoot height did not show any height increment. The time taken for the seedlings to became asymptotic in growth and attain maximum size was taken as the suitable nursery period for each species. (Table 1)

Table 1. Nursery period and growth rates of the three mangrove species

\begin{tabular}{|c|c|c|c|c|}
\hline \multirow{3}{*}{ Species } & \multicolumn{4}{|c|}{ Nursery period of seedlings (Week) } \\
\hline & \multicolumn{4}{|c|}{ Substrate type } \\
\hline & $\begin{array}{l}\text { Mangrove } \\
\text { soil }\end{array}$ & $\begin{array}{l}\text { Mangrove soil } \\
\text { (1): Sand (1) }\end{array}$ & $\begin{array}{l}\text { Terrestrial } \\
\text { soil }\end{array}$ & $\begin{array}{l}\text { Terrestrial soil (1): } \\
\text { Mangrove soil (1) }\end{array}$ \\
\hline R. apiculata & 14 & 14 & 16 & 15 \\
\hline B. sexangula & 16 & 16 & - & - \\
\hline C. tagal & 14 & 14 & 14 & 14 \\
\hline
\end{tabular}

Variation of shoot height with time revealed that $R$. apiculata initiates an asymptote after 14 weeks of seedling growth, indicating further growth under the nursery conditions is marginal. $R$. apiculata seedlings therefore could preferably be transplanted after 14 weeks. However when seedlings were grown on terrestrial soil and terrestrial soil (1): mangrove soil (1) combination, the suitable nursery growth periods are 16 weeks and 15 weeks respectively. $R$. apiculata seedlings therefore could preferably be transplanted after 14 weeks. Observations on the other two species indicate that $B$. sexangula can be transplanted after 16 weeks while $C$. tagal after 14 weeks.

All three mangrove species showed their best germination on mangrove soil while Mangrove soil (1): Sand (1) combination produced the second best germination (Table 2).

Table 2. Percentage survival of mangrove seedlings with different potting media

\begin{tabular}{lcccc}
\hline \multirow{2}{*}{ Species } & \multicolumn{4}{c}{ Percentage germination of seeds } \\
\cline { 2 - 5 } & $\begin{array}{l}\text { Mangrove } \\
\text { soil }\end{array}$ & $\begin{array}{l}\text { Substrate type } \\
\text { Mangrove soil } \\
\text { (1): Sand (1) }\end{array}$ & & $\begin{array}{l}\text { Terrestrial soil } \\
\text { Terrestrial soil (1) } \\
\text { : Mangrove soil } \\
\text { R. apiculata }\end{array}$ \\
B. sexangula & 100 & 100 & 60 & 60 \\
C. tagal & 60 & 40 & 0 & 0 \\
\hline
\end{tabular}


R. apiculata and C. tagal germinated on Terrestrial soil (1) and Mangrove soil (1) implying that these two species could potentially be used as potted ornamental plants.

Table 3. Growth rates of the three mangrove species

\begin{tabular}{|c|c|c|c|c|}
\hline \multirow{3}{*}{ Species } & \multicolumn{4}{|c|}{ Mean Growth rate (Shoot height $(\mathrm{cm}) /$ Month) } \\
\hline & \multicolumn{4}{|c|}{ Substrate type } \\
\hline & $\begin{array}{l}\text { Mangrove } \\
\text { soil }\end{array}$ & $\begin{array}{l}\text { Mangrove soil } \\
\text { (1): Sand (1) }\end{array}$ & $\begin{array}{l}\text { Terrestrial } \\
\text { soil }\end{array}$ & $\begin{array}{l}\text { Terrestrial soil } \\
\text { (1): Mangrove } \\
\text { soil (1) }\end{array}$ \\
\hline R. apiculata & 4.15 & 3.39 & 3.04 & 3.23 \\
\hline B. sexangula & 3.75 & 2.87 & 0 & 0 \\
\hline C. tagal & 0.56 & 0.4 & 0.11 & 0.26 \\
\hline
\end{tabular}

Growth of seedlings of the mangrove species during 30 week period (Table 3) revealed that seedlings performed best i.e. shoot length increase in mangrove soils, i.e. $4.15 \mathrm{~cm} /$ month for $R$. apiculata, $3.75 \mathrm{~cm} /$ month for $B$. sexangula and $0.56 \mathrm{~cm} /$ month for $C$. tagal (Plate 2), while mangroves soils mixed with sand, produced the second best growth for $B$. sexangula and $C$. tagal, nevertheless, Terrestrial soil (1): Mangrove soil (1) combination for $R$. apiculata was of less favourable for the purpose. Seedlings grown on terrestrial soils showed the lowest growth rate for all three mangrove species.

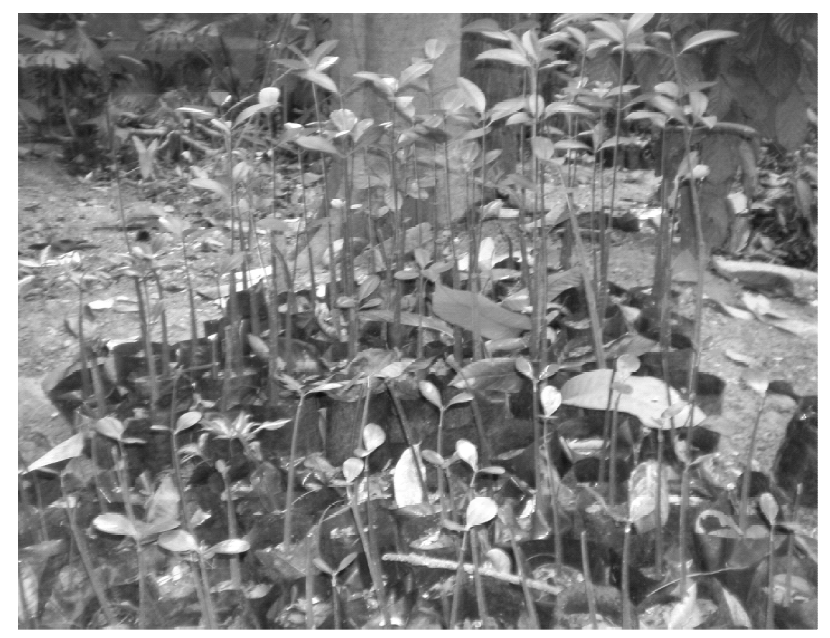

Plate 2. Mangrove plants grown in different growth media in the nursery 


\section{Discussion}

Vegetative propagation methods produce plants with identical genotype with the mother plant (Selvam et al. 2005). During the present study, it was possible to produce three saplings from a $20 \mathrm{~cm}$ long $R$. apiculata propagule. Hence hormone treated propagule cuttings provide a reasonable means for mass production of $R$. apiculata propagules but not for A. corniculatum of which the seedling cuttings did not survive. This might probably be due to using seedlings which have not been sufficiently mature for the purpose.

The differential root regeneration capacities of different growth hormones individually or in combination, might depend on their respective capacities for the regeneration and elongation of roots (Ghosh and Basu 1974). The large number of root primodia induced by the root promoting hormones act as effective metabolic sinks, drawing on the nutritional reserves of the cuttings for their growth and development (Das et al. 1996). Most shoot growth from propagule cuttings was similar to that of the controls and hence it is evident that propagule cuttings can grow well to some extent without having external hormone treatments, may be due to the presence of endogenous hormones that can bring about shoot promotion.

Almost all the propagule cuttings of A. coniculatum treated with these three types of hormone combinations died. These propagules are smaller in size and they are more fragile than $R$. apiculata and $C$. tagal propagules. One of the main reasons for this failure may be that the propagules were not mature enough to produce new plants. Rarity of $A$. corniculatum also made the task of finding mature propagules difficult.

All stem cuttings of A. marina and $R$. apiculata treated with these three types of hormones died. With A. marina shoots were initiated in few cuttings 10-15 days after planting. But they wilted few days later because of lack of development of shoot system.

Hormone treated air layers of A. marina and $R$. apiculata did not produce roots even after six months. Selvam et al. (2005) recorded that $93 \%$ rooting response from IBA $(1500 \mathrm{ppm})$ treated $R$. apiculata propagule cuttings, $42 \%$ rooting response from IBA $(2500 \mathrm{ppm})$ treated $R$. apiculata and A. marina air layers, $48 \%$ rooting response from IBA $(2000 \mathrm{ppm})$ treated $R$. apiculata and $A$. marina and $56 \%$ rooting response from IBA $(2000 \mathrm{ppm})$ treated A. marina stem cuttings. The best rooting response has been observed when stem cuttings of Heritiera forms and Heritiera littoralis were treated with $5000 \mathrm{ppm}$ IBA (Das et al. 1996). However, Tomlinson (1986) reports that air layering of mangroves has often failed. The varied response of the cuttings suggested that the endogenous promoters and inhibitors greatly determine the nature of interaction with the exogenously applied auxins (Roy et al. 1972).

Soils physically support plants, and acts as reservoirs for the water and nutrients. The soil texture (mixture of particle sizes) and soil structure (particle arrangement in aggregates) determine how well plant roots may grow in the soil and obtain from it the necessary water, air, and mineral nutrients (Anon. 1978). Results of the present study reveal that the best growth media for all mangroves seedlings under nursery conditions is mangrove soil and the second best combination for $B$. 
sexangula and $C$. tagal was mangrove soil (1): sand (1) combination, while mangrove soil (1): terrestrial soil (1) combination was suitable for $R$. apiculata. Although the performance of mangroves in different potting media was as above, a statistically significant difference in performance could not be found. Results thus indicate that mangroves can also be grown in pots with media other than mangrove soils. Mangrove plants therefore could be grown in pots for decorative purposes in terrestrial environments.

None of the B. sexangula was able to grow on both terrestrial soil and mangrove soils separately, nevertheless (1): terrestrial soil (1) combination supported seedling growth. Generally B. sexangula would prefer to grow on substrates with well drained and not on heavy clayey soils (De Silva and De Silva 2006), thus indicating that this is a potential species that can be used for ornamental purposes.

However all seedlings grown on terrestrial soils showed the lowest growth rate for all three mangrove species, indicating that no other soil than from mangroves is ideal for mangrove nurseries. Since neither growth rates nor mean shoot heights of seedlings were significantly different at the 0.05 confidence level, for $R$. apiculata and $C$. tagal, any of the above growth media could be used as nursery growth media for these two species. Hence the results indicate mangrove nurseries for these two species can be constructed even in non mangrove areas.

Variation of shoot height with time revealed that $R$. apiculata initiates an asymptote after 14 week of seedling growth, indicating further growth under the nursery conditions is unnecessary. $R$. apiculata seedlings therefore could preferably be transplanted after 14 weeks of nursery care. Observations on the other two species indicate that $B$. sexangula can be transplanted after 16 weeks while $C$. tagal after 14 weeks.

\section{Conclusion}

$R$. apiculata can be propagated through propagule cuttings. IBA (1000 $\mathrm{ppm})$ is the best hormone concentration for inducing best root and IBA (1500 ppm) for best shoot production from propagule cuttings of $R$. apiculata. A. corniculatum propagule cuttings could not be used for vegetative propagation. Air layering and stem cuttings, treated with growth hormones is unsuccessful in vegetative propagation of $A$. marina and $R$. apiculata. Mangrove soils as well as mangrove soils (1): sand (1), terrestrial soil alone and mangrove soil (1): terrestrial soil (1) can be used as nursery growth media for $R$. apiculata and $C$. tagal. Variation of shoot height with time revealed that $R$. apiculata initiates an asymptote after 14 week of seedling growth, indicating further growth under the nursery conditions is not necessary. $R$. apiculata seedlings therefore could preferably be transplanted after 14 weeks of nursery care. Observations on the other two species indicate that $B$. sexangula can be transplanted after 16 weeks while $C$. tagal after 14 weeks.

\section{Acknowledgements}

Authors are thankful to National Science Foundation of Sri Lanka for funding this project. 


\section{References}

Alongi M.D. 2002.

Present state and future of the world's mangrove forests. Journal of Environmental Conservation 29 (3): 331-349.

Amarasinghe, M.D. \& S. Vidanage 2007.

Best Practice Guidelines for Restoration of Mangroves. ISBN 978-955-

8177-64-8. World Conservation Union (IUCN), Sri Lanka Country Office,

Colombo.

Anonymous 1978.

Soil: Physical Environment and how it affects plant growth, Division of Agricultural Sciences, University of California.

Dahdouh- Guebas, F., M. Verneirt, J.F. Tack, D. Van-Sprebroeck \& N. Koedam 1998.

Propagule predators in Kenyan mangroves and their possible effect on regeneration. Marine and Freshwater Research 49: 345-350.

Das, A.B., U.C. Basak \& P.Das 1996.

Metabolic changes during rooting in pre-girdled stem cutting, air layering of Heritiera. Botanical Bulletin of Academia Sinica 38: 91-95.

de Silva, P.K. \& M. de Silva 2006.

A Guide to the Mangrove Flora of Sri Lanka, WHT publication, Sri Lanka.

Gosh, S.K. \& R.N. Basu 1974.

Metabolic changes during the regeneration of roots on cuttings. Indian Journal of Biology 12: 166-168.

Minchinton, T.E. 2001.

Canopy and substratum heterogeneity influence recruitment of the mangrove Avicennia marina. Journal of Ecology 69:888-902

Peter, J.C. \& A.K. Raelee 2002.

The effect of seed predators on the recruitment of mangrove. Journal of Ecology 90: 728-736.

Roy, B.N., R.N. Basu \& T.K. Rose. 1972.

Interaction of oxine with growth redarding, inhibiting and ethylene producing chemicals in rooting of cutting. Journal of Plant Cell Physiology. 13: 1123-1127.

Selvam, V.R., T. Karunagaran, R. Ramasubramanian, P. Eganathan \& A.K. Parida 2005 .

Toolkit for Establishing Coastal Bioshield. M.S. Swaminathan Research Foundation, Chennai. $120 \mathrm{p}$.

Soni, N.K. 2010.

Plant growth and development. In: Fundamentals of Botany, Vol. 2. TATA

McGraw-Hill education, New Delhi, 197p.

Tomlinson, P.B. 1986.

The Botany of Mangroves. Cambridge University Press, Cambridge, UK. $126 \mathrm{p}$. 